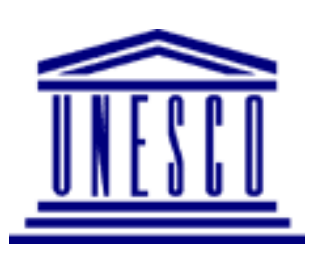

\title{
UNITED NATIONS EDUCATIONAL, SCIENTIFIC AND CULTURAL ORGANIZATION
}

Addressing the Ethical Dimensions of the Information Society in the process of Building Inclusive Knowledge Societies

\author{
Opening Remarks \\ by \\ Mr. Boyan Radoykov \\ Information Society Division \\ on the occasion of the Regional Conference on \\ "The Ethical Challenges of the Information Age: an African perspective" \\ Republic of South Africa
}

5 February 2007 
$\mathrm{Mr} / \mathrm{Ms}$ Chairperson,

Ladies and Gentlemen,

I am particularly pleased to be able to address your Conference on behalf of the DirectorGeneral of UNESCO, who, despite his great interest, was unable to attend it personally, due to prior commitments.

As you know, UNESCO is the UN body responsible for international cooperation in the field of education, science, culture and communication, which was founded in order to contribute to peace, security and democratic development, to increase and diffuse knowledge, to enhance mutual understanding and to further universal respect for justice and for human rights.

We, as an Organization, are committed to the full implementation of the fundamental freedoms proclaimed in the Universal Declaration of Human Rights and other universally adopted legal instruments, and UNESCO is the recognized leader within the UN System for promoting the implementation of Article 19 of the Universal Declaration of Human Rights concerning the right to freedom of opinion and expression. It is clear that frontier-free information society provides almost unlimited opportunities for the practical implementation of the Article 19, but it also poses great challenges.

Nor should we forget Article 12 of the Universal Declaration which states: "No one shall be subjected to arbitrary interference with his privacy, family house or correspondence, nor to attacks upon his honour and reputation. Everyone has the right to the protection of the law against such interference or attacks", and which reflects the basic rules of ethics that should be adopted and respected by everyone - participant in, and beneficiary form, the information society.

Thus, UNESCO has not only an interest but also an imperative institutional commitment to work in the field of ethics of information by promoting respect for fundamental values and principles, increasing awareness about information ethics and contributing to the 
formulation of national and regional strategies and policies in this field. Since 1997, UNESCO initiated a series of events enabling specialists and decision-makers to address the ethical dimensions of the information society. The main goal of the UNESCO INFOethics Congresses, organized in 1997, 1998 and in 2000, was to stimulate the reflection and the debate on the ethical, legal and societal aspects of the information society by bringing together participants from the largest possible number of countries representing the widest range of educational, scientific, cultural and social environments.

In the context of the constant expansion of Internet and the potential of new emerging technologies to facilitate interaction and to generate and acquire know-how, the issue of ethics remains of critical importance. The advent of ICTs has opened up new horizons in education and learning, employment opportunities, social and political interaction, and selfdetermination. This illustrates well the reason why UNESCO promotes universal access to ICTs as a key strategy which then determines access to information and knowledge with due respect to existing and universally accepted ethical principles and values.

\section{Ladies and Gentlemen,}

In my remarks, I should also like to share with you our strong conviction that knowledge is a key force in transforming societies, based on democratic principles. We are well aware that the ability to apply knowledge is boosting social and economic development worldwide. This is why, it is the main target of the capacity-building agenda in developing countries and is reflected in the huge investments being made in all industrialized economies in education, science and technology.

The concept of knowledge societies, which UNESCO is advocating, offers a comprehensive framework with a clear development-oriented perspective that captures the complexity and dynamism of current global trends and prospects. Knowledge societies require an 
empowering social vision which encompasses plurality, inclusion, solidarity and participation. UNESCO's position is therefore that we should strive for societies that recognize the need for supporting knowledge development, particularly local knowledge creation and access to knowledge, and that uphold cultural and linguistic diversity.

UNESCO recognized this global phenomenon by adopting the theme of Building Knowledge Societies in its key message to the World Summit on the Information Society (WSIS) and gave another perspective to it by emphasizing a more holistic approach and humanizing effect.

As you certainly know, the WSIS process ended with the decision that UNESCO will be in charge of coordinating the implementation of several Action Lines of the Geneva Action Plan and namely Action Line C10, which underlines the importance of the ethical dimensions as a key factor for the development of an Information Society that would contribute to building inclusive knowledge societies.

As a result, and in accordance with the Tunis Agenda for the Information Society, a first consultation meeting on Action Line C10 was convened by UNESCO in Paris on 17 October 2006 in order to:

- facilitate the initial sharing of views among stakeholders on their priorities and expertise in the implementation of Action Line C10;

- exchange ideas and opinions on the Action Line and its relation to other Action Lines, and on ways for its practical implementation;

- discuss the proposed terms of reference for facilitators as well as the proposed working methods for the "Multi-stakeholder Team".

Furthermore, in conformity with the standard setting role of UNESCO, we decided to contribute to the elaboration of possible ethical behavioral parameters and a proposal of a 
Code of ethics for the information Society has been drafted and discussed during the regional Info-Ethics meeting for Latin America held last December in the Dominican Republic. However, it would be hazardous to try to propose any rules of ethical conduct without prior and very broad consultation process. This is why, the draft Code of Ethics will be presented during this Conference and during all similar events that we intend to organize in 2007 and 2008.

Moreover, in our cooperation with Member States we do our utmost to facilitate reviewing, adapting and updating existing policies and strategies relating to the ethical dimensions, in order to help them facing the constantly evolving challenges in this domain. In this regard, the Infoethics Survey of Emerging Technologies prepared at the request of UNESCO aims at providing an outlook to the ethical implications of future communication and information technologies. The report further aims at alerting UNESCO's Member States and partners to the increasing power and presence of emerging technologies and draws attention to their potential to affect the exercise of basic human rights. This study also underlines that these days all decision makers, developers, the corporate scholar and users are entrusted with a profound responsibility with respect to technological developments and their impact on the future orientation of knowledge societies.

All these different undertakings contribute to characterize even more comprehensively the issues at stake and the challenges we face, among which I should like to underscore the following:

Access to knowledge content on the interactive networks remains a key issue with various ethical, legal and societal aspects that require the full attention of the international community. Fostering the quality and reliability of information resources on these networks is an endeavour that can be carried out only with the participation of all, both from the private and public sectors, in close collaboration with the civil society. As a matter of fact, 
since the early nineties, the debate always focused on this fundamental question of access to information, as well as on a framework for action towards facilitating access to multilingual information in the public domain. After several years of intensive work, such a framework was created with the adoption by the General Conference of UNESCO in 2003 of the first normative instrument covering this field - the "Recommendation concerning the Promotion and Use of Multilingualism and Universal Access to Cyberspace".

Similarly, the issue of privacy seriously hangs over us all. We yearn for security, but we also want privacy. How much are we ready to trade off, when we are well aware that our every movement is tracked by the use of credit cards, highway tolls, telephone cards, hidden camera systems, etc. This being stressed, UNESCO is also concerned to protect both the privacy and the dignity rights to which every citizen is entitled. Those are equally well established rights in international and national law. Nevertheless, the increase in the use of technologies in governments, business and communities poses a serious threat to the respect of these rights. It is therefore, in our opinion, time to lay down some ethical principles and best practices on which policies and strategies on the application of fundamental human rights in cyberspace should rest.

Another example of major concern relates to the scope of UNESCO's objective to enhance human diversity in all its forms, including cultural and linguistic diversity, both tangible and intangible. The Organization, along with its constitutional mandate, has to build bridges between cultures and nations and to promote dialogue among civilizations. The preservation of the richness and diversity of the universal human heritage are concepts that are enshrined in many international texts and national constitutions and legislations. They should be reaffirmed as to their application to the cyberspace.

\section{Ladies and Gentlemen,}

Much remains to be done for addressing these and other important questions, for successfully promoting the awareness about the ethical dimensions and their social 
implications among decision-makers and all other major stakeholders, as well as for acknowledging and promoting the basic values and principles that are to be further enhanced in the information society such as: peace and democracy, free flow of information, freedom of expression, tolerance, cultural diversity, shared responsibility, solidarity, informed consent, etc.

This is why, in addition to the already mentioned Info-Ethics event for Latin America, and further to the holding of this first Conference for the African Continent, we are organizing in September 2007 a similar gathering for the European Region. All these regional consultations should allow to improve awareness about the challenges of ethics of information as well as to devise the modalities and the criteria of assessing at national and regional levels the efforts to improve the debate and the decision-making process on the above ethical issues and consequently for measuring the developments in the field of information ethics. They should also allow strengthening international cooperation and should lead towards the design and the implementation of pilot regional and inter-regional initiatives in this field.

It is mainly through such regional and international consultations that we can mobilize attention around our far-reaching objectives and I am pleased that UNESCO, in close cooperation with its members and partners can provide the opportunity for such platforms. You, the participants in this Conference, coming from all horizons with different cultural and educational backgrounds can assist us in building the necessary synergies and in delivering a strong message throughout the world about the importance of addressing the ethical issues we face.

In conclusion, allow me to assure you that UNESCO will firmly persist in supporting and promoting the "Ethical dimensions of the Information Society", which is one of the priorities of our Organization in the field of communication and information. 
Thanks to our joint efforts, I hope we will be able to continue to play a crucial role in this important area in order to meet the constantly growing needs and legitimate expectations of people for justice and fair dealing in the information age.

I am confident that your contributions to this debate will reinforce the magnitude of the issues under consideration and I wish you all success in your deliberations.

I thank you for your attention. 